\title{
Assessment of the Authenticity of Herbal Dietary Supplements: Comparison of Chemical and DNA Barcoding Methods
}

Authors

Rahul S. Pawar, Sara M. Handy, Raymond Cheng, Nicole Shyong, Erich Grundel

\author{
Affiliation \\ Office of Regulatory Science, Center for Food Safety and \\ Applied Nutrition, U.S. Food and Drug Administration, \\ College Park, MD, USA
}

\author{
Key words \\ dietary supplements, HPLC, DNA barcoding, adulteration, \\ label claims
}

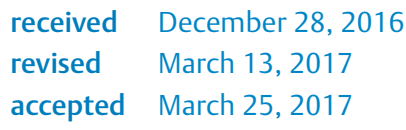

\begin{abstract}
About $7 \%$ of the U.S. population reports using botanical dietary supplements. Increased use of such supplements has led to discussions related to their authenticity and quality. Reports of adulteration with substandard materials or pharmaceuticals are of concern because such substitutions, whether inadvertent or deliberate, may reduce the efficacy of specific botanicals or lead to adverse events. Methods for verifying the identity of botanicals include macroscopic and microscopic examinations, chemical analysis, and DNA-based methods including DNA barcoding. Macroscopic and microscopic examinations may fail when a supplement consists of botanicals that have been processed beyond the ability to provide morphological characterizations. Chemical analysis of specific marker compounds encounters problems when these compounds are not distinct to a given species or when purified reference standards are not available. Recent investigations describing DNA barcoding analysis of botanical dietary supplements have raised concerns about the authenticity of the supplements themselves as well as the appropriateness of using DNA barcoding techniques with finished botanical products. We collected 112 market samples of frequently consumed botanical dietary supplements of ginkgo, soy, valerian, yohimbe, and St. John's wort and analyzed each for specific chemical markers (i.e., flavonol glycosides, total isoflavones, total valerenic acids, yohimbine, and hypericins, respectively). We used traditional DNA barcoding techniques targeting the nuclear ITS2 gene and the chloroplast gene psbA-trnH on the same samples to determine the presence of DNA of the labelled ingredient. We compared the results obtained by both methods to assess the contribution of each in determining the identity of the samples.
\end{abstract}

\section{Introduction}

A recent survey has shown that about half of adults in the U.S. report that they used at least one dietary supplement within the past thirty days [1,2]. More specifically, about $7 \%$ of the survey population reported use of botanical dietary supplements, with a common reason for their use identified as "to improve overall health" [1]. A recent survey on the use of complementary and alternative medicine found that an estimated 40.6 million U.S. adults used herbal preparations and supplements [3]. This increased use of botanical supplements has led to intense discussions related to their authenticity and quality [4]. Reports of adul- teration of such products with materials of substandard quality or with pharmaceuticals are of concern because such substitutions, whether inadvertent or deliberate, may reduce the efficacy of specific products or lead to adverse events [5].

Dietary supplements marketed in the U.S. are regulated under the Dietary Supplement Health and Education Act of 1994 [6]. Current Good Manufacturing Practices (CGMPs) for dietary supplements [7] require that manufacturers establish and provide verification that specifications are met for identity, purity, strength, and composition of their dietary supplements. The manufacturer is required to conduct at least one appropriate test or examination to verify the identity of a dietary ingredient before use in a supplement. Such tests may include any appropriate test 
with sufficient specificity to determine identity, including chemical and laboratory tests, gross organoleptic analysis, microscopic identification, or analysis of constituent markers [7]. However, the FDA's regulations do not list methods that must be used to meet the manufacturer's established specifications on the grounds that any such method could become obsolete [7]. This implies that each botanical preparation may require a specific scientifically valid authentication method in order to provide the necessary proof of compliance with this requirement [8]. The further implication that methods deemed to be appropriate at a given time will continually evolve is inescapable.

Macroscopic and microscopic examinations are the classic means of verifying the identity of fresh whole plants and plant parts. In some cases, these techniques may also be applicable to dried or processed plant material. However, under many circumstances, macroscopic or microscopic examinations will fail because a preparation consists of multicomponent powdered samples that have been processed beyond the ability to provide morphological characterizations [9]. Use of alternate techniques becomes necessary in order to identify and authenticate such complex samples. Chemical methods, such as HPLC, LC-MS, GC-MS, HPTLC, etc., that measure specific "marker" compounds, which are distinct for a given species, are widely used. However, the lack of availability of commercial standards is a major limiting factor that hinders the widespread adoption of such chemical methods for authentication of botanical preparations [9]. Khan and Smillie [9] provided examples of the types of efforts required to understand the complexity of botanical samples and noted that the intricacies involved in extracting, fractionating, isolating, and unambiguously identifying constituents are often overlooked. In recent years, the chemical fingerprinting techniques that use statistical evaluation tools are increasingly applied to dietary supplements. These methods often use chromatographic data from HPLC, GC-MS, or LC-MS analysis or spectroscopic data from an MS, NMR, UV, or IR experiment. A representative collection of authentic plant samples are needed to develop a "fingerprint" for authentication purposes, however this approach is best suited for a single-component finished product.

Genetic fingerprinting and profiling are rapidly developing approaches to botanical identification $[8,10]$. The use of DNA-based techniques to identify organisms by comparing a small portion of their DNA sequence to a known sequence is well accepted in other fields, including, among many others, biodiversity studies, food authenticity, and monitoring of the illegal trade of animals/products [11]. Many researchers [12-14] have discussed DNA-based identification techniques and their possible limitations for authentication of plants used in herbal medicine and dietary supplements.

Recent investigations describing DNA barcoding analysis of dietary supplements have raised concerns about the authenticity of botanical dietary supplements themselves as well as the appropriateness of using DNA barcoding techniques with finished botanical products. Newmaster et al. [15] reported a DNA barcoding study in which the $r b c L$ and ITS2 gene regions were sequenced in each of the 44 herbal products. Though they were able to produce DNA barcodes for $91 \%$ of the products, $59 \%$ were found to contain sequences of plants not listed on the product labels. New- master et al. [15] also reported varying degrees of product substitution, and the presence of fillers and contaminants in these products. Subsequent studies and critiques $[14,16]$ brought attention to the applicability of traditional DNA barcoding for analysis of finished dietary supplement products. Parveen et al. [14] noted that problems can occur with regard to quality of DNA, primer affinity, PCR amplification, sequencing of amplicons, and lack of appropriate reference databases for comparison.

In this investigation, we collected 112 market samples of botanical dietary supplements labelled to contain ginkgo [Ginkgo biloba L. (Ginkgoaceae)], soy [Glycine max L. Merr, (Fabaceae)], valerian [Valeriana officinalis L. (Valerianaceae)], yohimbe [Pausinystalia johimbe K. Schum. (Rubiaceae)], and St. John's wort [Hypericum perforatum L. (Clusiaceae)]. We analyzed each for specific chemical markers (i.e., flavonol glycosides, total isoflavones, total valerenic acids, yohimbine, and hypericins, respectively) and used traditional DNA barcoding targeting the nuclear ITS2 gene and the chloroplast gene psbA-trnH to determine the presence of DNA of the labelled ingredient. We compared the results obtained by both methods to ascertain the relative contribution of each in determining the identity of the samples.

\section{Results and Discussion}

All products carried the Supplement Facts label, which is required for dietary supplements under U.S. dietary supplement labeling regulations [17]. We selected products that belong to the most frequently consumed categories and, where possible, listed single ingredients and whose labels provided information on the content of the marker compounds of interest. Ginkgo products $(n=20)$ were labelled to contain ginkgo leaf or extract and two contained other botanical ingredients (e.g., dong quai, cayenne, pine bark extract, gotu kola). Labels of soy dietary supplements $(n=22)$ stated the presence of soy isoflavones, soy, or soy germ extract and one product also contained the botanical ingredient Radix puerariae. Valerian supplements $(n=24)$ were labelled to contain valerian root or valerian root extract and five were also labelled as containing other botanical ingredients (e.g., passion flower, hops, lemon balm). Yohimbe products ( $n=23$ ) were labelled as containing yohimbe bark, its extract, or pure yohimbine. St. John's wort products $(n=23)$ were labelled as containing $H$. perforatum parts (e.g., aerial parts, flowering tops, flowers) or $H$. perforatum extract.

The amounts of specific chemical marker compounds were not always stated on product labels. While some products explicitly stated the amount of marker compounds, e.g., "14.4 mg flavone glycosides" or "soy isoflavones $40 \mathrm{mg}$ ", for others, we estimated the quantitative amounts of the marker compounds from the amount of extract and percentage of marker compounds stated on the label (Table S1, Supporting Information). The expected amounts of marker compounds per serving were estimated from the weights of tablets or capsules and from serving size statements on product labels. The results obtained from the chemical analyses are expressed as $\mu \mathrm{g} / \mathrm{g}$ and as \% of label claims ( $\bullet$ Tables 1-5). 


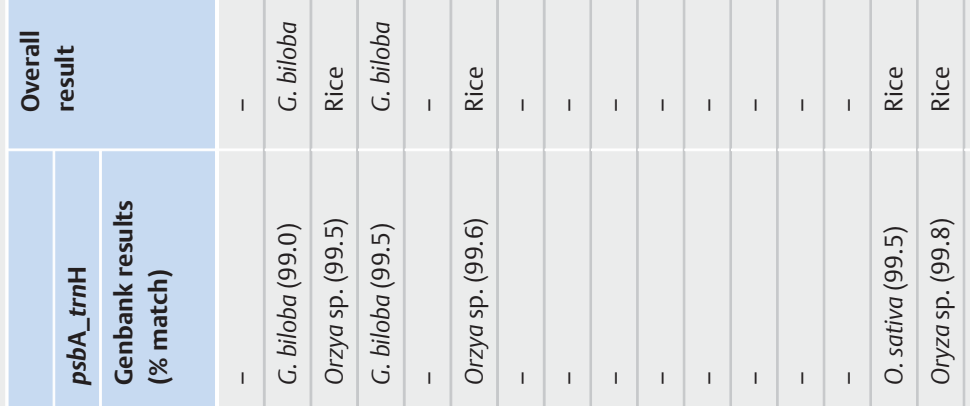

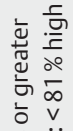

œ

蒫产

点

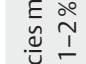

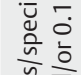

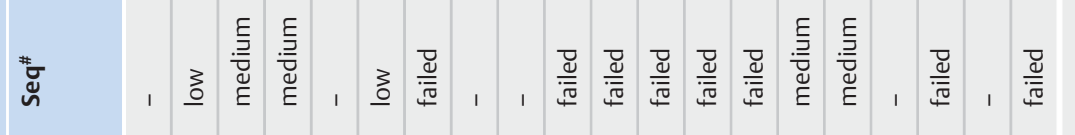

बiv

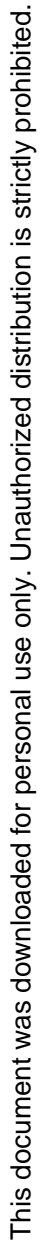

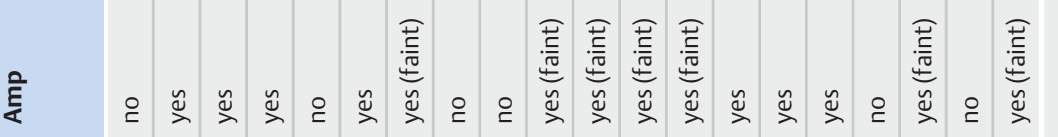

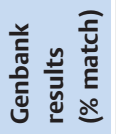

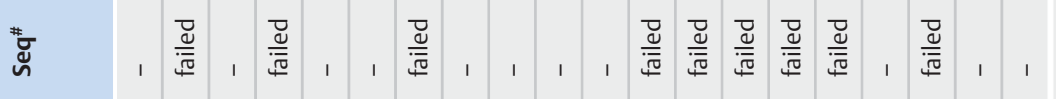

돌

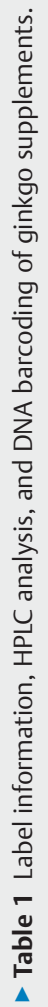

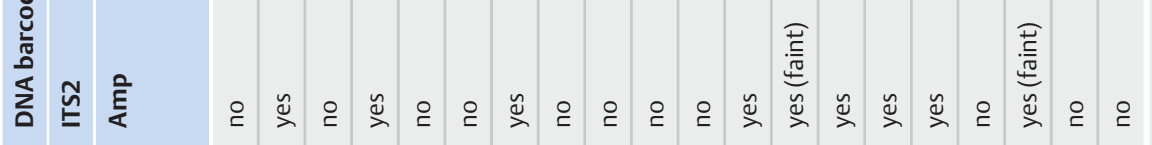

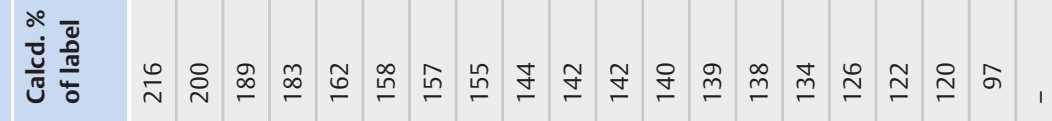

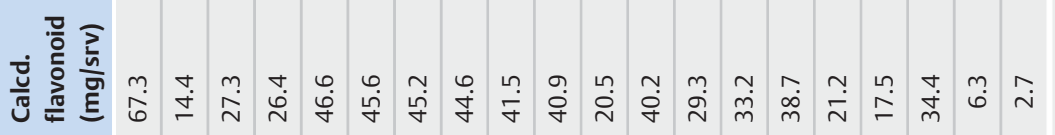

峞

官 这

嵌

in

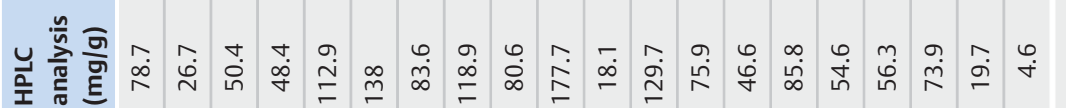

$\frac{\pi}{4} \frac{\pi}{\frac{\pi}{\pi}}$

戈育

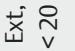

可

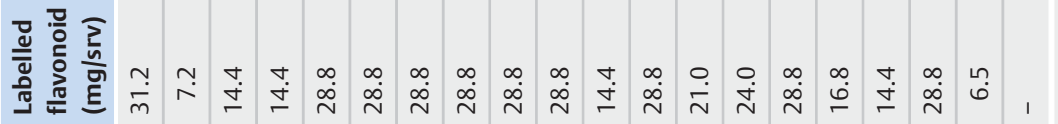

至 
Existing HPLC methods were adapted for the quantitative analysis of specific marker compounds in five types of botanical dietary supplements. The chemical structures of these markers can be found in Fig. S1, Supporting Information. These methods were rapid (run times $<20 \mathrm{~min}$ ), provided good linearity for the regression curves, and were highly reproducible. The purpose of this investigation was to use validated methods from the literature to analyze samples rather than to develop new methods. We performed spike recovery studies and analyzed NIST SRM's, when available, to verify the performance of the methods. The results of analysis of NIST SRMs provided evidence of the accuracy of the methods for the specific marker compounds of interest (Table S2, Supporting Information).

The HPLC method used for ginkgo supplements measured the amounts of total glycosides based on the sum of the aglycones quercetin, kaempferol, and isorhamnetin obtained following acid hydrolysis. The correlation coefficients $\left(R^{2}\right)$ were $>0.999$ for all analytes in the range of 1 to $120 \mu \mathrm{g} / \mathrm{mL}$. Recovery experiments were conducted by spiking product 12 ( $\triangleright$ Table 1) with 2000 and $8000 \mu \mathrm{g} / \mathrm{g}$ each of quercetin and kaempferol, and 500 and $2000 \mu \mathrm{g} / \mathrm{g}$ of isorhamnetin. Recoveries $(n=4)$ for these analytes were $80-88 \%$.

Ginkgo-containing dietary supplements were labelled as containing ginkgo extracts, dried leaf, or a combination of both. One product was formulated as liposomes that were prepared from a standardized gingko extract. Most of the products were labelled as containing $24-26 \%$ flavonoids and 5-7\% triterpenes. Nineteen of the 20 products carried label statements for their flavonoid contents ( $\triangleright$ Table 1 ) and claimed to provide $6-31 \mathrm{mg}$ flavonoids/ serving. Our HPLC analysis showed that these products would provide $3-67 \mathrm{mg}$ flavonoids/serving. Thus, all of the products met or exceeded their label statements for flavonoid content.

It has been reported that commercial ginkgo extracts may be adulterated with other flavonoid- rich extracts to increase their flavonoid content $[18,19]$. Chandra et al. [19] recommended the combination of a qualitative determination of unhydrolyzed extracts as well as a quantitative analysis for total flavonol glycosides, including quercetin/kaempferol/isorhamnetin ratios, in hydrolyzed extracts to establish or track the authenticity of extracts. Similarly, Avula et al. [18] considered that measurement of the flavonoid composition without a prior hydrolysis step is a good analytical approach because it can provide assurance that the supplement has not been adulterated with either flavonol aglycones or flavonol glycosides.

In addition to its requirement for the measurement of flavonoid glycosides, USP now also prescribes an assessment to determine adulteration of ginkgo with flavonoid-rich extracts. This specification requires the calculation of the ratios of quercetin, kaempferol, and isorhamnetin in the hydrolyzed extracts [20]. The ratio of the kaempferol peak to the quercetin peak should not be less than 0.7 and the area of the peak of isorhamnetin should not be less than 0.1 times the area of the quercetin peak. Though none of our ginkgo products carried the USP seal, we analyzed our results according to these new USP specifications and found that 15 products appeared to have the specified flavonol ratios while ratios in five products $(4,5,12,15$, and 16$)$ showed deviations in one or both of the ratios ( $\triangleright$ Table 6 ).
Chandra et al. [19] suggested that ginkgo extracts could be adulterated with extracts of Styphnolobium japonica (L.) Schott. (Fabaceae), which is also known as Sophora japonica. S. japonica is reported to contain the isoflavone genistein and its glycosides [21]. Avula et al. [18] showed that authentic samples of ginkgo do not contain genistein. Thus, the presence of genistein in ginkgo extracts is suggestive of adulteration with S. japonica. In order to examine this parameter with our ginkgo supplements, we modified our HPLC method by using the detection wavelength of $260 \mathrm{~nm}$ in addition to the primary wavelength of $370 \mathrm{~nm}$. This provided enhanced sensitivity for the detection of a genistein peak if this were present in extracts of the supplements. The peak for pure genistein appeared at 4.6 min and we found that 16 of 20 products $(80 \%)$ contained measureable concentrations of genistein ( $\triangleright$ Table 6 ). The presence of genistein in these products was further confirmed by LC-MS/MS analysis with the genistein standard (Table S3, Supporting Information). We also determined the presence of the ginkgo terpenes in all the products using the HPLC-ELSD method described in Table S3, Supporting Information. The presence of bilobalide, ginkgolides $A-C$, and ginkgolide J was observed in all of the extracts of the products showing that specific markers of ginkgo were found in all of the products (data not shown). Avula et al. [18] also reported the presence of bilobalide and ginkgolides in all the ginkgo supplements they analyzed.

Chemical analyses of ginkgo products provide several means of detecting potential adulteration. However, use of such methods alone does not provide conclusive proof that adulteration has occurred. Specifically, while quantitative analysis provides reliable information on a product's flavonoid content, it does not provide evidence as to whether flavonoid-rich extracts have been added to bolster the flavonoid content. Use of a flavonol ratio analysis on the same data provides additional information if the extracts have been adulterated with non-ginkgo-containing extracts. In the present study, while 16 products showed the presence of genistein, only five of those showed deviations in their flavonol ratios. While an analysis to detect genistein provides information suggestive of the addition of S. japonica extracts, it is in itself insufficient to determine whether extracts other than S. japonica have been added.

For the analysis of soy-containing dietary supplements, twelve isoflavones that included the isoflavone glycosides genistin, daidzin, and glycitin, the aglycones genistein, daidzein, and glycitein, and the acetyl- and malonyl-glycoside forms of genistein, daidzein, and glycitein were measured in 22 supplements. The method provided resolution of all peaks of interest. The $\mathrm{R}^{2} \mathrm{~s}$ were greater than 0.999 for all analytes in the range of 1.6 to $40 \mu \mathrm{g} / \mathrm{mL}$. Recovery experiments were conducted by spiking product $13(\triangleright$ Table 2) with four concentrations, between 0.7 and $2.7 \mathrm{mg} / \mathrm{g}$, of the six isoflavone standards. Recoveries $(n=4)$ of $94-109 \%$ were observed. The method was further evaluated by analysis of NIST SRM 3238 (Soy-Containing Solid Oral Dosage Form). Our analysis found mean values between 95 and $102 \%$ for these six analytes, demonstrating the accuracy of the method for measurement of the isoflavone content in our samples (Table S2, Supporting Information).

While the labels of many of the dietary supplements in our study listed a specific content of isoflavones, e.g., "soy isoflavones 


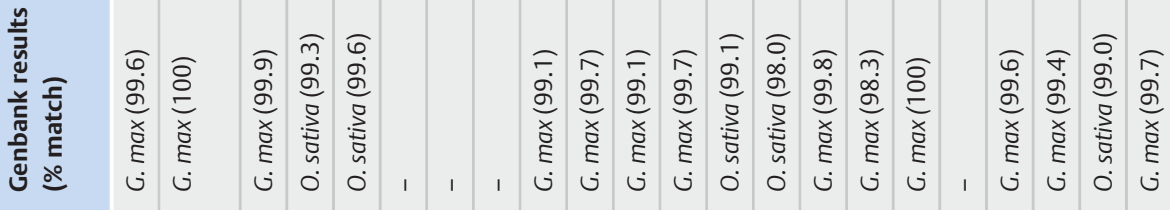
定

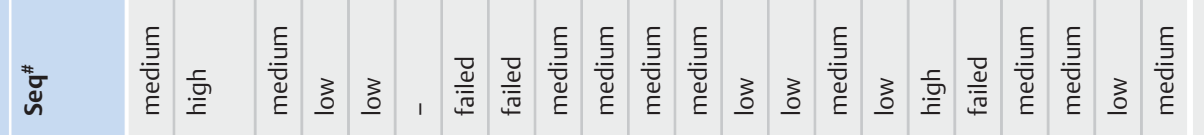

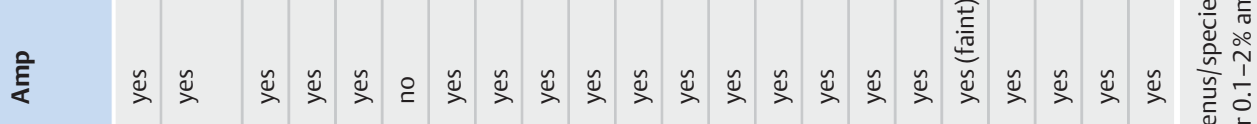

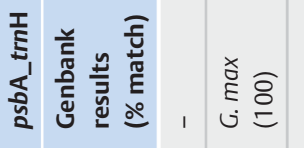

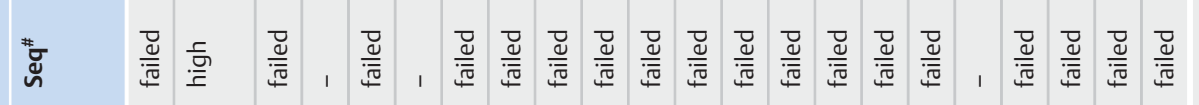
离 $\frac{\grave{c}}{\bar{D}}$ 흐 을 产

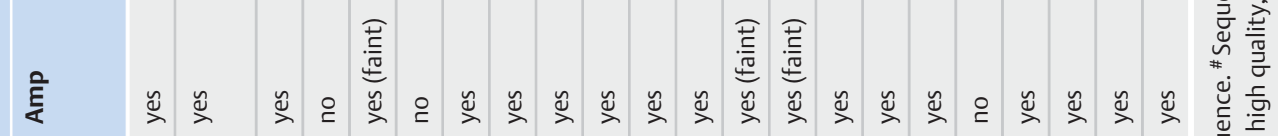

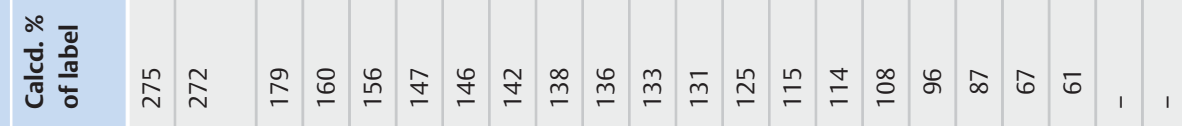

\section{을 끌}

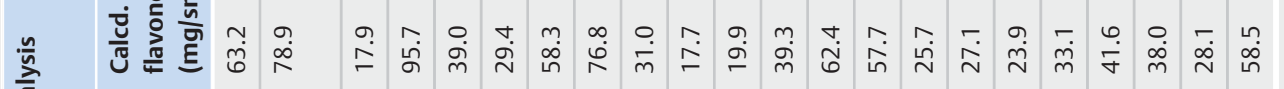

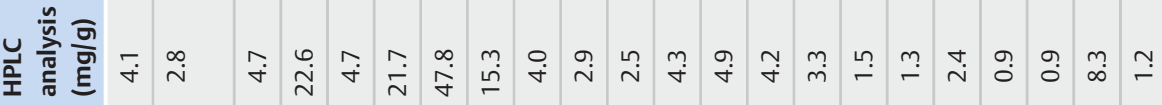

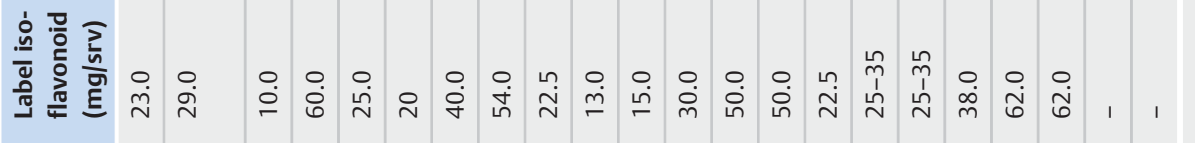


$40 \mathrm{mg}$ ", others listed a weight of the extract that contained a specific percentage of isoflavones (e.g., "Soybean extract $1000 \mathrm{mg}$, standardized to contain $2.5-3.5 \%$ isoflavones"). Two products did not make a specific statement on their labels regarding their isoflavone content. In products that listed the amount of extract containing a specific percentage of isoflavones, we estimated the expected isoflavone content from label information. Label statements of isoflavone content varied from 10 to $62 \mathrm{mg} /$ serving $(\vee$ Table 2 ). All products showed the presence of some combination of the 12 isoflavones used as standards in the analysis. Estimated amounts of isoflavones ranged from 17.7 to $95.7 \mathrm{mg} / \mathrm{serv}$ ing and from 61 to $275 \%$ of amounts declared on the product labels ( $\triangleright$ Table 2 ). Eighteen of 20 products (90\%) met or exceeded the amounts of isoflavones listed on their labels. There are no specifications for the amounts or types of individual isoflavones that should be expected in isoflavone supplements. While the relationship between total quantities analyzed and amounts declared on product labels can be determined, conclusions that relate the label declarations to the specific isoflavone profiles found in the products analyzed cannot be drawn.

The method used for analysis of valerian supplements measured the amounts of valerenic acid, hydroxyvalerenic acid, and acetoxyvalerenic acid as total valerenic acids. A conversion factor was used to estimate the amount of hydroxyvalerenic acid and acetoxyvalerenic acid [22]. The method provided sufficient resolution of the peaks when USP powdered valerian extract was analyzed. The method showed good correlation coefficients in the concentration range of 0.5 to $133 \mu \mathrm{g} / \mathrm{mL}$ with $R^{2}$ values $>0.999$. Recovery experiments conducted by spiking product 19 ( $\vee$ Table 3) with the valerenic acid standard at $50 \mu \mathrm{g} / \mathrm{g}$ and $125 \mu \mathrm{g} / \mathrm{g}$ concentrations showed recovery values of $94-97 \%(n=4)$.

The dietary supplements of valerian were labeled to contain root powder, extract of valerian root, or a combination of both. While labels of some products stated the amount of valerenic acid present, other labels stated the \% of valerenic acids in the extract. Among the 24 products analyzed, only one product, a combination of leaf material and extract, was found to be devoid of any valerenic acids ( $\triangleright$ Table 3 ). In several cases, product labels were not clear about whether the content information applied to valerenic acid itself or to total valerenic acids. For the purpose of consistency, we treated the amount declared on product labels as total valerenic acids. The labels of 12 products (50\%) did not include any statements of their valerenic acid contents. Among the remaining twelve products, only one was found to contain total valerenic acids at a concentration below the labelled amount. Most products exceeded their label claims. Many products that exceeded the labelled concentrations contained both roots and extract. In these products, only the valerenic acid content of the extract was stated on the product labels.

For the quantification of yohimbine in yohimbe supplements, we used the chromatographic conditions described by Lucas et al. [23], which provided satisfactory separation of yohimbine from other indole alkaloids in the samples. The injection of yohimbine standards at various concentrations provided an acceptable linear response in the range of 40 to $1060 \mu \mathrm{g} / \mathrm{mL}$. $R^{2}$ values were $>0.999$. Recovery experiments conducted by spiking product 19
( $\triangleright$ Table 4) with $1.0 \mathrm{mg} / \mathrm{g}$ and $1.5 \mathrm{mg} / \mathrm{g}$ yohimbine $(\mathrm{n}=4)$ provided recovery values between $84-90 \%$.

Labels of dietary supplements of yohimbe stated that the products contained yohimbe extract $(14 / 23,61 \%)$, pure yohimbine $(8 / 23,35 \%)$, or yohimbe bark (1/23, 4\%). Labels of 20 of 23 products $(87 \%)$ carried claims regarding their content of yohimbine and three did not $(\vee$ Table 4$)$. In products labelled as containing pure yohimbine, the labelled concentrations ranged from 2.5 to $5.1 \mathrm{mg} /$ serving. Results of our analysis showed that all 23 products contained yohimbine at concentrations ranging from 0.5$12.4 \mathrm{mg} /$ serving. The yohimbine contents of the products ranged from $9-150 \%$ of the labelled amount and 15 products (65\%) met or exceeded their label claims. Similar results were reported by Cohen et al. [24]. Among a total of 49 yohimbine-containing supplements, yohimbine contents were found to range from 0 $12.1 \mathrm{mg}$ per recommended serving/day. Analyzed contents ranged from 23 to $147 \%$ of label statements for the 11 products $(22 \%)$ that listed a specific quantity of yohimbine on their labels [24]. Lucas et al. [23] analyzed ten dietary supplements of yohimbine and found that three (30\%) contained no detectable yohimbine. The highest concentration of yohimbine found was $29.5 \mathrm{mg} /$ $\mathrm{g}$ in a capsule product [23]. The two bark samples included in the study of Lucas et al. [23] contained 10.7 and $13.6 \mathrm{mg} / \mathrm{g}$ yohimbine. A sample of authentic yohimbe bark from the American Herbal Pharmacopeia analyzed in another study was found to contain $13.95 \pm 0.18 \mathrm{mg} / \mathrm{g}$ yohimbine [25].

The USP method for powdered St. John's wort extract [26] was adapted for use in extraction of hypericins from St. John's wort supplements. Instead of using USP powdered St. John's wort for calculation of hypericins, we used standard curves of hypericin to calculate the amounts of hypericin and pseudohypericin in the supplements. The method provided sufficient resolution of hypericin and other eluted peaks. The method showed good correlation coefficients with $R^{2}$ values $>0.999$. Recovery experiments conducted by spiking product 20 with the hypericin standard at $125 \mu \mathrm{g} / \mathrm{g}$ and $500 \mu \mathrm{g} / \mathrm{g}$ provided recovery values $(\mathrm{n}=4)$ of $83-$ $89 \%$. The accuracy of the analysis of the NIST SRM 3264 St. John's wort methanol extract was $85 \%$ for hypericin and $110 \%$ for pseudohypericin (Table S2, Supporting Information).

We analyzed 23 products for their total hypericin content ( $\triangleright$ Table 5). Twelve products were formulated with St. John's wort extract alone while five contained the flowers, herb, or aerial parts of the plant. The remaining six products contained St. John's wort extract and plant parts. Some extracts and plant part-containing products were labelled as standardized to contain $0.3 \%$ hypericin. Nineteen products (83\%) were labelled with their hypericin content while the remaining four products (17\%), which all contained aerial plant parts, did not make claims for their hypericin content. Only one product formulated with plant parts alone made a claim for its hypericin content (0.3-0.5\%).

HPLC analysis ( $\triangleright$ Table 5 ) showed that all products contained hypericin in amounts ranging from 0.1 to $1.2 \mathrm{mg} /$ serving. Only two products met their label claims, while two products contained less than $10 \%$ of the labelled amount. Shah et al. [27] analyzed six commercial preparations of St. John's wort and found that products contained 8 to $39 \%$ of the amounts of total hypericin claimed on their labels. Stability studies indicated that the 


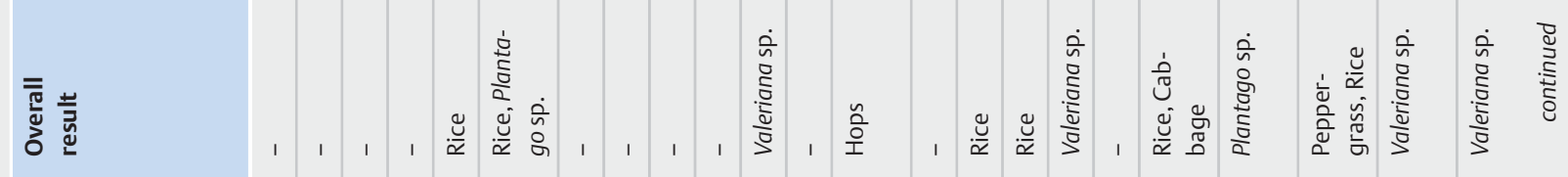

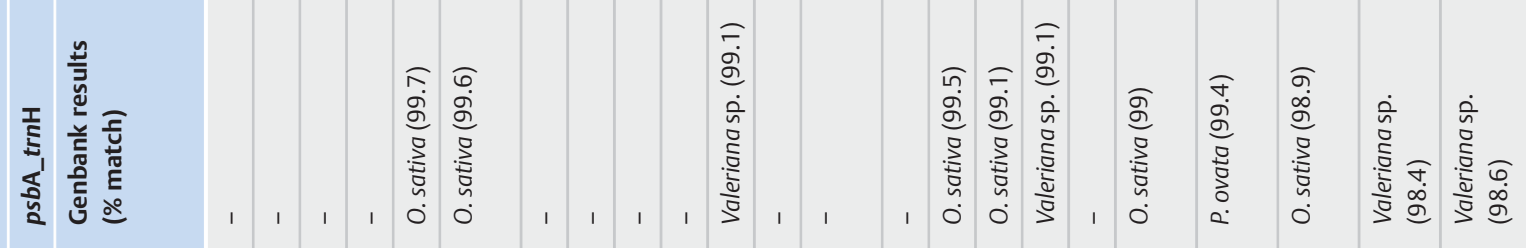

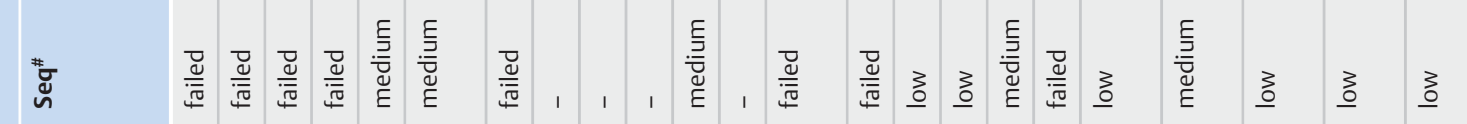

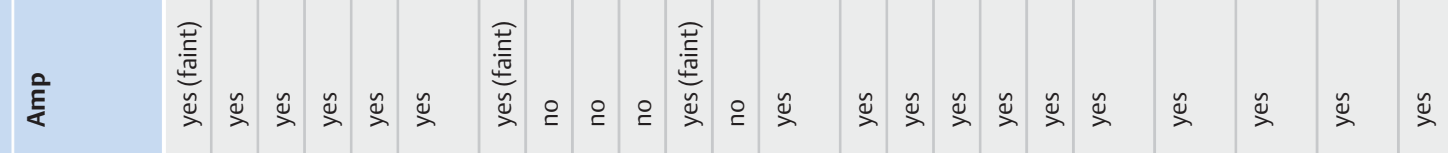

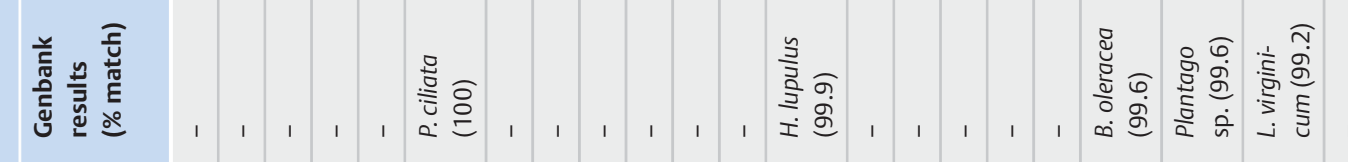

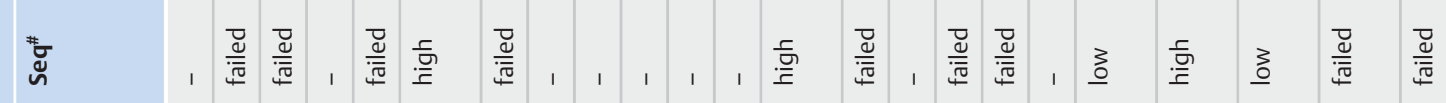

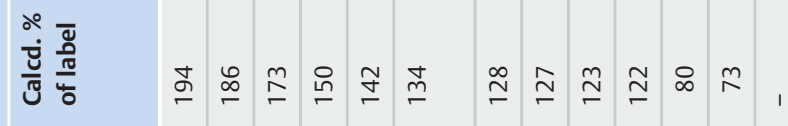

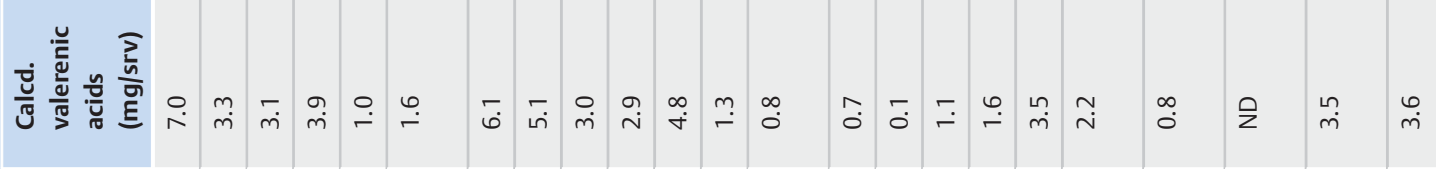

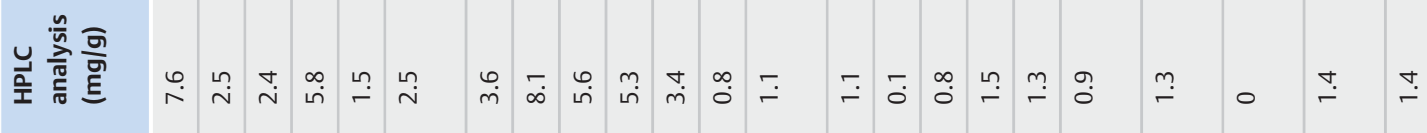

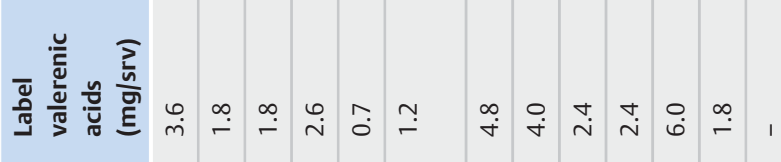

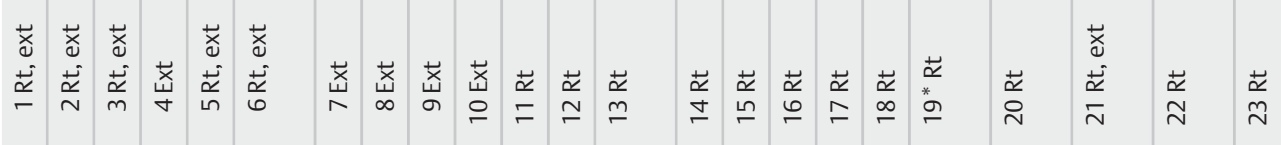




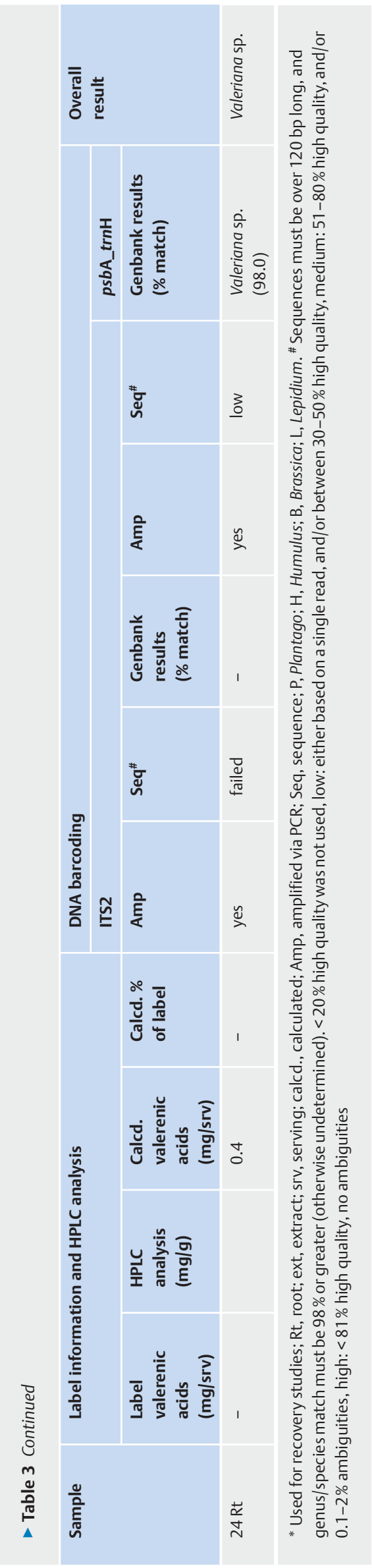

content of marker compounds decreased significantly with time [27]. Results of the analysis of NIST SRM 3264 may also suggest stability issues for hypericin, but we have not pursued this rigorously. Nevertheless, because of recognized stability issues, careful consideration may be needed in interpreting \% label claim values. In our study, all of the products carried expiration or "best by" dates. All products were analyzed within their stated expiration dates.

All supplements were subjected to DNA barcoding analysis. Following their extraction, DNA was visualized on a $1.2 \% \mathrm{gel}$ in order to better understand the size of the DNA extracted from the dietary supplements. Among the 112 samples analyzed, eight (7.1\%) had high molecular weight DNA over 10 kilo bases (kb), four (3.6\%) had DNA sizes of $2 \mathrm{~kb}$, and 17 (15.0\%) had fragmented DNA of $<500$ bases. No DNA was visible on the gels for the remaining 83 samples (74.1\%). PCR is a very sensitive technique, however, and it is still possible for the reaction to work, even if no DNA is visible on the gels. The sizes of DNA extracted serve to illustrate that much of the DNA obtained from dietary supplements may be fragmented into sizes that make it difficult for full-length DNA barcoding to work well. The type of product (capsules, tablets containing plant material, or extract) will also make a difference in the success of DNA extraction. In cases where DNA is highly fragmented, a "mini-barcoding" or next generation sequencing (NGS) approach, which targets a smaller region, could potentially be more successful. However, our goal in this manuscript was to evaluate "traditional" DNA barcoding and thus, we did not attempt to evaluate other DNA-based methods.

Six samples were initially used to compare two Qiagen extraction kits. Among the six samples, the Qiagen plant kit yielded two PCR products and the Qiagen stool kit yielded three (data not shown). Based on these results, the remainder of the samples was extracted with the stool kit. Two primer sets were used for amplification from these products. Over all, the $p s b A$-trnH primer set produced a greater number of amplifications $(73,65.2 \%)$ than did the ITS2 region $(62,55.4 \%)$. In three cases, samples showed the presence of DNA from another supplement in the study. These samples were reextracted and resequenced to verify the results. In all three cases, the reruns were negative for DNA (data not shown). All samples that were expected to contain plant material (e.g., intact plant material rather than extracts) were reextracted and rerun if they were found to be negative on the first pass. In all of these cases, the results of the reruns were consistent with those of the original findings (data not shown).

During the DNA barcoding analysis of Ginkgo ( $\triangleright$ Table 1 ) using ITS2, 9/20 (45\%) of samples were amplified with PCR, but no usable sequences were generated. When psbA-trnH was used, 14/20 (70\%) of the samples were amplified and six usable sequences were generated, ranging in length from 197-564 base pairs (bp). Four of these were positive for Orzya sativa (rice), which was listed on each of the labels, and two (products 2 and 4 ) were positive for ginkgo DNA. These two were labelled as containing leaf material. Our chemical analysis shows that product 2, which listed only leaf on its label, did not show genistein, and its flavonol ratios were found to be in the acceptable range ( $\bullet$ Table 6 ).

The results show that, though DNA of G. biloba was not detected in most of the ginkgo extract-containing supplements, all extracts showed the presence of ginkgo flavonoids. These results 


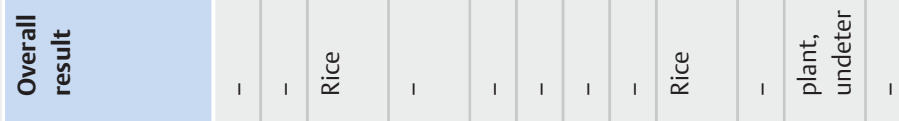

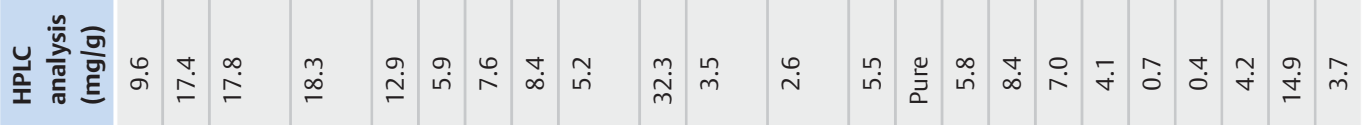

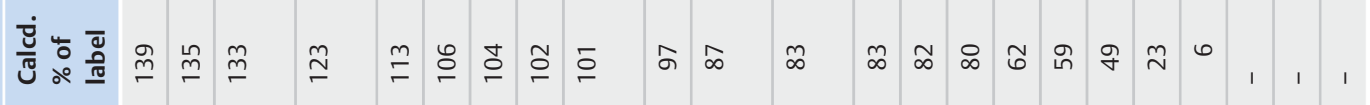

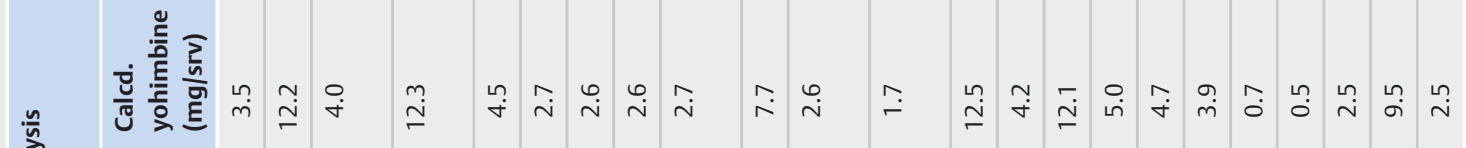
공 
are similar to those reported recently by Ivanova et al. [28] in which the two samples of gingko extract-containing supplements analyzed by NGS for the ITS2 region did not yield DNA sequence data, while the expected chemical markers were observed during LC-MS analysis. In another investigation, which did not clearly describe the nature of the supplements, five of seven ginkgo supplements showed the presence of G. biloba DNA using ITS2 and rbcL primers [15].

The DNA barcoding analysis of soy-containing supplements ( $\vee$ Table 2 ) showed that among 22 products, DNA from 19 (86\%) was amplified by PCR using the ITS2 target. However, all but one (463 bp in length) failed sequencing. Product 2 was positive for soy. Using the psbA-trnH target, 21 of 22 (95\%) were amplified by PCR, yielding 18 sequences ranging in length from 169557 bp. Among these, 13 were found to be soy and five were found to be rice, the latter of which was also listed on product labels. In summary, 13 products (59\%) showed evidence of soy DNA. When a product label listed a rice component as an excipient, the result of the DNA barcoding was rice (i.e., in five of six products). We also observed that most of the products that were labelled as containing concentrate or extract of soy germ showed evidence of soy DNA.

During DNA barcoding analysis of valerian supplements, the ITS2 target was amplified in 15/24 samples (63\%). However, only five of these could be sequenced and these sequences ranged in length from 132-495 bp. Use of the target psbA-trnH provided greater success in identification of Valeriana species. Twenty of 24 samples (83\%) were amplified by PCR and 13 of those provided usable sequence data with fragments ranging in length from 124$574 \mathrm{bp}$. Five products were shown to contain DNA of Valeriana species ( $\triangleright$ Table 3 ). One product showed evidence of the presence of Humulus lupulus L. (Cannabaceae), which was listed on the product label. However, a number of products showed the presence of plants such as Plantago species, Brassica oleracea L. (Brassicaceae), and Lepidium virginicum L. (Brassicaceae), which were not listed on their labels. We also observed, primarily with use of the psbA-trnH target, the presence of rice DNA in six products among the eight products whose labels listed rice as an ingredient. The chemical markers of valerian were not found in product 21, which showed the presence of $L$. virginicum DNA.

During DNA barcoding analysis of yohimbe supplements, we found no evidence of the presence of yohimbe DNA in any of the products ( $\triangleright$ Table 4$)$. While the ITS2 target was amplified in five of 23 samples (22\%), none of the sequenced DNA led to identifications. Similarly, the psbA-trnH target was also amplified in seven of 23 samples (30\%), with three passing sequences ranging in length from 561 to 577 bp. In only two samples was the DNA conclusively identified as that of rice. Rice was listed as an ingredient in these products. Nine of the 23 products (39\%) were labelled as containing only pure yohimbine. Thus, we did not expect to identify DNA of $P$. johimbe in these samples. One sample of bark and 14 extract-containing products did not show evidence of DNA. DNA analysis of any kind may not be the best tool to use for supplements of yohimbe since such products contain either bark, which is known to have low amounts of DNA [29], and/or extracts from which it is often difficult to collect DNA [14].
Results of DNA barcoding of St. John's wort supplements showed that, when compared with the other four botanicals in our analysis, the ITS2 target provided more successful amplification (15/23, 65\%) and sequencing of $H$. perforatum DNA (six out of eight sequences, 330-504 bp obtained) than did the psbA-trnH target $(13 / 23,57 \%)$ amplifications. Of the 12 psbA-trnH sequences (135-573 bp) obtained from these amplifications, none were determined to be $H$. perforatum ( $\bullet$ Table 5 ). Use of the psbA-trn H primer resulted in the identification of rice and other undetermined plants (<98\% Genbank match) in the products. Among the 23 products analyzed, only five (22\%) showed evidence of the presence of St. John's wort DNA ( $\bullet$ Table 5 ). The investigation of Newmaster et al. [15] reported the presence of $H$. perforatum DNA in three of five products they barcoded with ITS2 and rbcL. However, it was not clear whether the products analyzed by Newmaster et al. [15] contained extracts or plants parts. The investigation of Ivanova et al. [28], which targeted the ITS2 gene using NGS, reported finding $H$. perforatum DNA in all three of the supplements tested, whereas use of the Sanger sequencing method found DNA in only one.

In the case of product 23 ( $\vee$ Table 5 ), our DNA analysis could provide conclusive identification down to the species level because the two primers provided different results. We recorded a 99.9\% match to $H$. perforatum using the ITS2 target and a $99.5 \%$ match to $H$. punctatum using the $p s b A-t r n H$ target. This result may be due to the limitation of the database, to the quality of our DNA sequence, or because these targets may not be the most appropriate for use in separating these two species. It has been reported that $H$. perforatum and $H$. punctatum both contain anthraquinone compounds such as hypericin and pseudohypericin. Thus, chemical analysis of the products will not be of help in determining which of the two Hypericum species is present in a specific product [30]. Further investigation will be needed to determine whether St. John's wort supplements may be adulterated by formulating them with a locally available and possibly cheaper raw material such as $H$. punctatum.

Among the 112 botanical dietary supplement products that we analyzed, 111 (99\%) contained chemical marker(s) expected from their label information. Ninety of the supplements (80.4\%) carried a quantitative label claim for specific markers and in 65 of these $(72.2 \%)$, the sum of the markers analyzed met or exceeded the amounts claimed on product labels ( $\vee$ Table 7 ). In contrast, results from the traditional DNA barcoding studies showed that only 25 of the products (22\%) showed evidence of the presence of the botanical material named on the product label.

HPLC analysis showed that $99 \%$ of the dietary supplements analyzed contained at least some of the expected marker compounds. However, this does not mean that these products were authentic because the presence of an expected marker may not indicate the presence of the relevant extract or labelled plant material. For example, our results with ginkgo products suggest that not all of these products were authentic. We found flavonol ratios outside of the expected ranges in seven of the ginkgo products and 17 of the products were found to contain genistein. This finding suggests the adulteration of ginkgo extracts to boost their flavonoid contents. While chemical methods are widely used to analyze botanical supplement materials, the results must be critically 


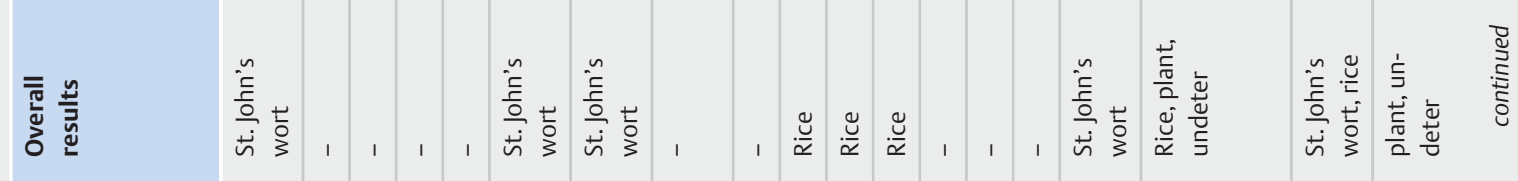

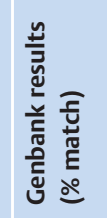

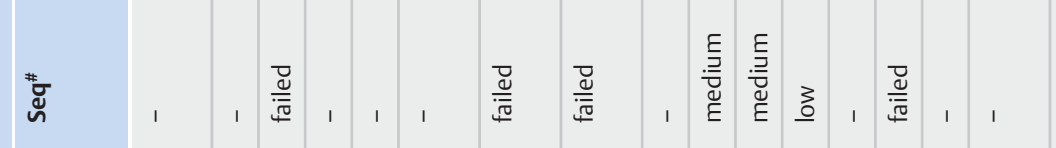

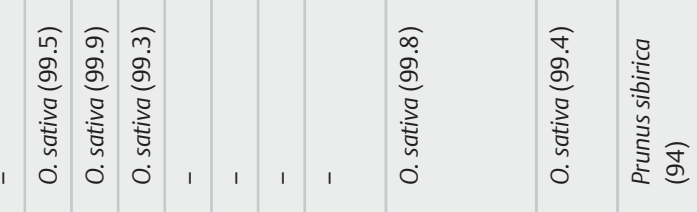

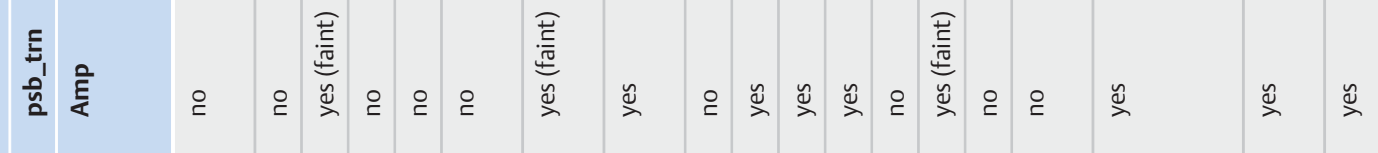

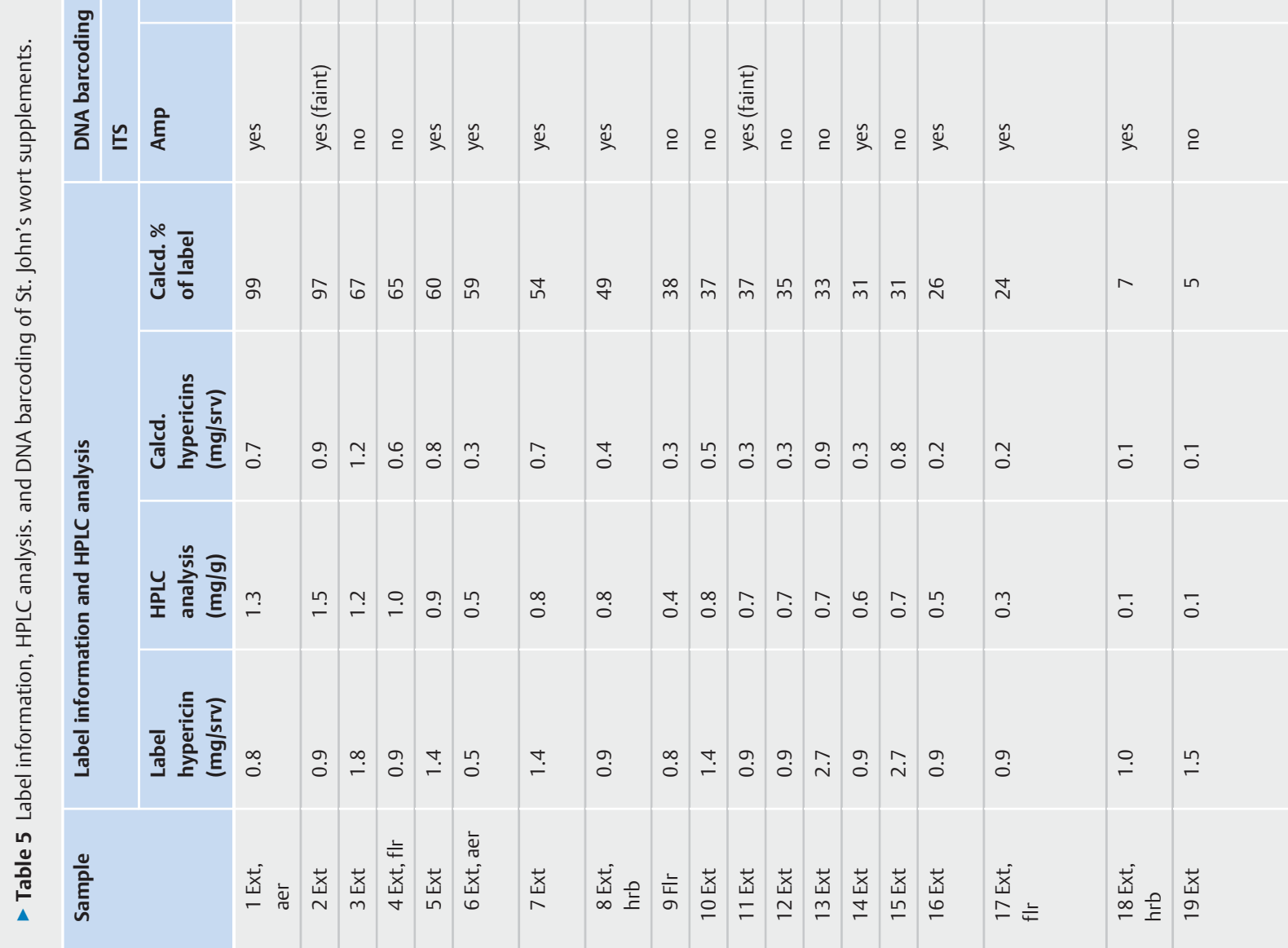




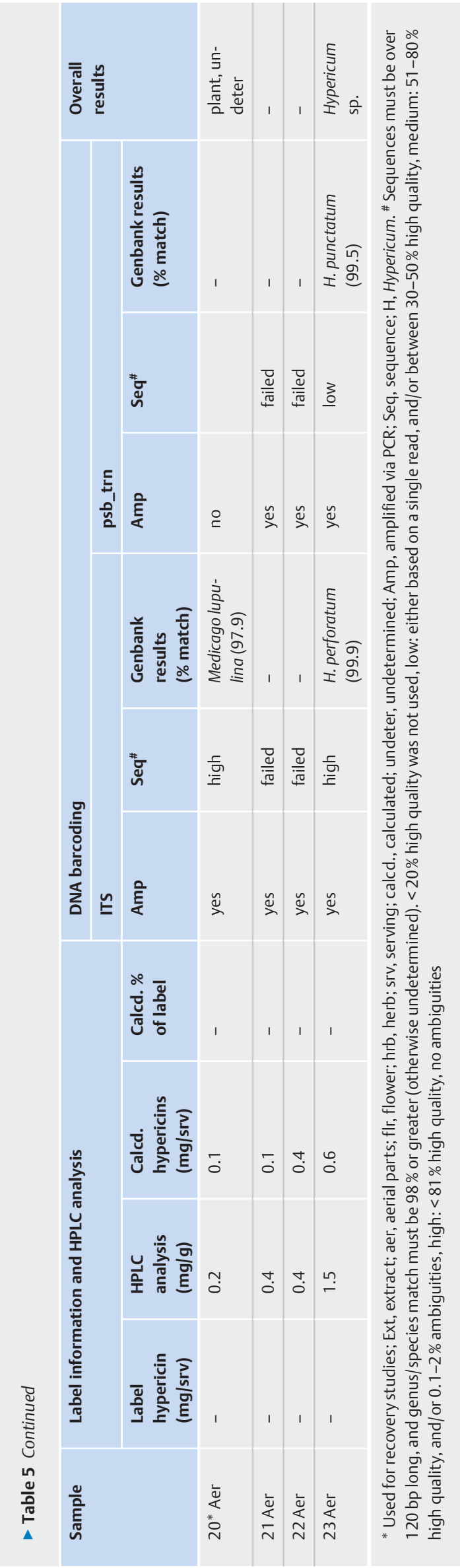

evaluated and additional analyses may need to be applied in order to avoid incorrect conclusions.

Chemical fingerprinting of botanical materials requires a significant investment in basic research to develop a truly representative set of authenticated specimens from multiple populations but the resultant methods are invaluable in identifying and authenticating botanical dietary supplements [8]. Utilization of statistical programs such as hierarchical cluster analysis or principal component analysis to evaluate chromatograms (in full or in part) of specific samples against a compiled population of authenticated reference samples is a logical extension of phytochemical fingerprinting. Such an approach has been described by Soares and Scarminio [31] and Harnly et al. [32].

Much lower levels of successful identifications of the botanical ingredient were observed in our set of samples using the DNA barcoding method, with only 25 of the 112 products (22\%) providing a positive identification. Soy supplements provided the highest relative number of successful identifications (13/22, $59 \%$ ) despite the fact that all were labelled as formulated with soy extracts. Ginkgo supplements were primarily composed of extracts and positive identifications were made only in the cases of two products labelled as containing leaf material. Valerian supplements consisted largely of root material but failed to yield many positive outcomes. DNA was not found in any of the yohimbe supplements, many of which contained pure yohimbine or appeared to contain highly processed extracts. Positive identifications were made in only half of the St. John's wort supplements that were labelled to contain plant parts. Thus, attempts to predict the likely success of DNA barcoding with a specific product may be frustrating because the mere presence of plant material may not result in greater positive identification, while some extract-containing supplements may retain sufficient DNA for a positive identification.

Traditional DNA barcoding may fail with finished dietary supplement products because of fragmented or poor quality DNA or lack of suitable primers [14]. In our work, we found many cases in which amplification was not followed by the generation of usable sequences. In such cases, the samples may have been mixtures of several botanicals. This could arise from the inclusion of excipients such as rice, or possibly from adulteration (whether incidental or accidental). It should also be noted that the use of other gene targets could potentially provide more success in identifying the botanical species in dietary supplements. However, the targets chosen for use in our studies had been successfully used in previous studies of medicinal plants [41]. In addition, there may also have been limitations of the database utilized for identification. For this latter reason, the FDA is developing a publically available database of chloroplast genomes derived from authenticated specimens.

Recently developed DNA-based methods might have been more successful in the cases in which traditional DNA barcoding was not effective. Little [33] used mini-barcodes and digital PCR to separate filler DNA and possible G. biloba DNA in supplements labelled as containing G. biloba leaf extract. They reported that usable DNA could be extracted from 30 of 32 samples (93.8\%) labelled as containing $G$. biloba leaf extract. They also reported that six of 37 supplements (16.2\%) analyzed by their technique contained fillers without any detectable G. biloba DNA [33] and made the important point that their matK mini-barcode assay could not 
- Table 6 Calculated flavonol ratios and presence of genistein in ginkgo supplements.

\begin{tabular}{|c|c|c|c|}
\hline \multirow[t]{2}{*}{ Sample } & \multicolumn{3}{|c|}{ HPLC analysis } \\
\hline & $\begin{array}{l}\text { Kaem/Quer } \\
\text { ratio }\end{array}$ & $\begin{array}{l}\text { Isor/Quer } \\
\text { ratio }\end{array}$ & $\begin{array}{l}\text { Genistein } \\
\text { detected }\end{array}$ \\
\hline 1 & 1.3 & 0.1 & yes \\
\hline 2 & 0.7 & 0.2 & no \\
\hline 3 & 0.8 & 0.1 & yes \\
\hline 4 & 0.4 & 0.1 & yes \\
\hline 5 & 0.4 & 0.1 & yes \\
\hline 6 & 0.8 & 0.1 & yes \\
\hline 7 & 0.8 & 0.2 & yes \\
\hline 8 & 0.8 & 0.1 & yes \\
\hline 9 & 0.8 & 0.1 & yes \\
\hline 10 & 0.7 & 0.1 & yes \\
\hline 11 & 1.1 & 0.2 & no \\
\hline 12 & 0.2 & 0.0 & yes \\
\hline 13 & 0.9 & 0.1 & yes \\
\hline 14 & 0.9 & 0.1 & yes \\
\hline 15 & 0.4 & 0.1 & yes \\
\hline 16 & 0.2 & 0.0 & yes \\
\hline 17 & 0.8 & 0.1 & yes \\
\hline 18 & 1.0 & 0.4 & yes \\
\hline 19 & 1.2 & 0.4 & yes \\
\hline 20 & 1.0 & 0.3 & no \\
\hline
\end{tabular}

Kaem, kaempferol; Quer, quercetin; isor, isorhamnetin. The ratios were calculated from the peak areas of kaempferol, quercetin, and isorhamnetin. Genistein was measured at $260 \mathrm{~nm}$

distinguish between samples that did not contain any G. biloba DNA and samples that contain G. biloba processed in a way that rendered the $G$. biloba DNA incompatible with PCR.

Other authors have also recommended the use of short minibarcode (<150bp) sequence libraries to increase the success of identifying botanical species in highly processed herbal products [13]. Use of digital PCR, NGS [34], or even small targeted PCR assays [35] may provide better success in attaining good quality sequences from highly processed extracts, products with fragmented DNA, or products containing multiple species. In the many samples that appear to contain little or no DNA, alternative extraction techniques may need to be investigated.

The work of Palhares et al. [36] illustrates the complexity of the issue of authentication of botanical dietary supplements. Palhares et al. investigated 257 samples of dried leaves, flowers, and roots from eight distinct species of botanicals approved by the World Health Organization for the production of medicinal herbs and that were available in a Brazilian market. Results from DNA barcoding (matK, rbcL, and ITS2 regions) indicated the level of substitutions might be as high as $71 \%$ [36]. Qualitative and quantitative chemical analyses (TLC, HPLC, UV spectroscopy) revealed situations in which the correct species was being sold but the expected chemical compounds were not present. To add further complex- ity, some samples identified as substitutions contained chemical compounds from the correct species at low concentrations. Palhares et al. [36] proposed that DNA barcoding be used as a first screening step in the authentication of medicinal plants because substitutions could be discarded and the expense of subsequent chemical analysis could be avoided.

Ivanova et al. [28] utilized both Sanger (i.e., traditional) and NGS for taxonomic authentication of 15 herbal supplements representing five medicinal plants (Echinacea purpurea, V. officinalis, G. biloba, $H$. perforatum, and Trigonella foenum-graecum). This work represents the first comprehensive evaluation of the performance of NGS for DNA-based authentication of herbal natural products. Based on the results of their studies, Ivanova et al. [28] concluded that Sanger sequencing should not be used for testing herbal dietary supplements because it is unable to resolved mixed signals from samples containing multiple species. In cases in which a contaminant template is preferentially amplified, Sanger sequencing may detect only the contaminant DNA and lead to biased or misleading outcomes. The NGS workflow described by Ivanova et al. [28] enabled the simultaneous detection of plant and fungal DNA. As such, their protocol can be utilized for screening for fungal contamination of raw botanical materials, quality assurance of raw botanical materials, and for assessing the purity of finished products [28].

To the best of our knowledge, this is the first study that compared information on dietary supplement labels with results obtained by chemical analyses and by traditional DNA barcoding. As shown with ginkgo supplements, chemical methods are not fully able to detect adulteration and there is a need to develop or extend existing analytical approaches to identify unexpected adulterants. Traditional DNA barcoding has been successful in plant identification and identification of adulteration or substitutions of botanical material with related or unrelated species. However, when applied to the analysis of finished products, traditional DNA barcoding often shows limited success and may provide unreliable results. Both chemical methods of analysis and traditional barcoding methods have been successful in appropriate circumstances of contributing to assessments of identity and authenticity of botanical supplements. However, newer chemical analytical approaches (e.g., principal component analysis) and use of minibarcodes or NGS show great promise and will be needed for analyzing complex botanical supplement products.

\section{Material and Methods}

\section{Reagents and chemicals}

HPLC grade acetonitrile, methanol, and water were purchased from Thermo Fisher Scientific. Hypericin (90\%), pseudohypericin (95\%), formic acid, anhydrous magnesium sulfate, and sodium chloride were purchased from Sigma-Aldrich and phosphoric acid from JT Baker. Reference standards (all 100\%) for kaempferol, quercetin, isorhamnetin, valerenic acid, yohimbine $\mathrm{HCl}$, oxybenzone, diadzin, genistin, glycitin, diadzein, genistein, glycitein, and apigenin were purchased from U.S. Pharmacopeial Convention. Ginkgo terpene lactones (Lot I0K042), powdered St. John's wort extract (Lot F0G245), and powered valerian extract (Lot FOL397) 


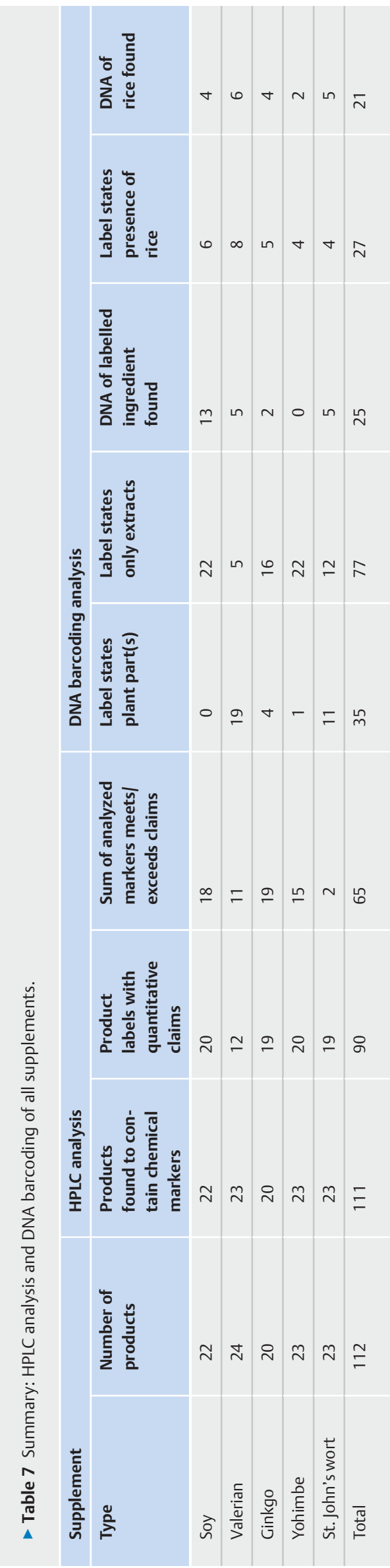

were also purchased from U.S. Pharmacopeial Convention. Soycontaining solid oral dosage form [Standard Reference Material (SRM) 3238], ginkgo-containing tablet (SRM 3248), G. biloba extract (SRM 3247), St. John's wort (H. perforatum L.), and methanol extract (SRM 3264) were purchased from the National Institute of Standards and Technology.

\section{Dietary supplements}

Dietary supplements of ginkgo were purchased from online vendors between December 2014 and June 2015. Soy, valerian, yohimbe, and St. John's wort supplements were purchased online between May 2015 and December 2015. The products $(n=112)$ were in tablet or capsule form. Twenty tablets or capsules from each bottle, representing at least $17 \%$ of its contents, were analyzed. Tablets were ground and mixed thoroughly to prepare a composite. Capsules were emptied and their contents were thoroughly mixed in a mortar and pestle. The handling of test portions of dietary supplement composites and of SRMs is described in Tables S2 and S3, Supporting Information.

\section{Quantitative HPLC methods}

Specific marker compounds in five types of botanical dietary supplements were quantitatively measured using HPLC methods. Previously described quantitative HPLC methods for ginkgo [37], soy isoflavones [38], valerian [22], yohimbine [39], and St. John's wort [40] were adapted and their detailed description is provided in Table S3, Supporting Information. The accuracy of the methods was determined by calculating \% recovery after spiking composites of a single commercial product for each type of supplement within the calibration range with standard compounds indicated in Table S3, Supporting Information. The accuracy of the methods was verified by analysis of NIST SRMs when available. Analyses were performed in four independent replicates. Recoveries were calculated with the formula: Recovery $(\%)=\left(C_{f}-C_{u} / 100 \times C_{a}\right)$ where $C_{a}$ is the calculated concentration added to the test sample and $C_{f}$ and $C_{u}$ are the concentrations of fortified and unfortified test samples, respectively.

\section{DNA barcoding}

DNA extraction: A small (six samples) comparative study was performed to evaluate the following DNA extraction kits: Qlamp DNA Stool mini-kit and the DNeasy Plant mini-kit (Qiagen, Inc.). In each case, DNA was extracted from $25-75 \mathrm{mg}$ of homogenized sample. The composite samples were the same as those used for the chemical analyses. Following this preliminary evaluation, 133 additional extractions, including some replicates, were carried out using the QIAamp DNA Stool mini-kit. The manufacturer's instructions were followed for all samples. Negative controls were included in each set of extractions (i.e., DNA extraction without added dietary supplement material). After extraction, $5 \mu \mathrm{L}$ of DNA, $2 \mu \mathrm{L}$ of $6 x$ Mass ruler DNA loading dye (Thermo Scientific), and $13 \mu \mathrm{L}$ of molecular grade water were combined from each sample and run on a precast $1.2 \%$ agarose E-gel with ethidium bromide according to the manufacturer's protocol on the E-Base Integrated power supply alongside a Fast Ruler High Range DNA Ladder (both from Thermo Scientific) to evaluate DNA presence and quality. 
Polymerase chain reaction (PCR): PCR Primers were selected based on those known to have a high success rate with medicinal plants [41]. These included the nuclear intergenic region ITS2: S2 F-5'-ATGCGATACTTGGTGTGAAT-3'/S3R-5'-GACGCTTCTCCAGACTACAAT-3' [41] and the chloroplast intergenic region psbAtrnH with the following primers: psbA-GTTATGCATGAACGTAATGCTC/trnH-5'-CGCGCATGGTGGATTCACAATCC-3' [42,43]. The PCR cocktail consisted of $6.25 \mu \mathrm{L}$ of $10 \%$ trehalose solution, $2 \mu \mathrm{L}$ of molecular grade $\mathrm{H}_{2} \mathrm{O}, 1.25 \mu \mathrm{L}$ of $10 \mathrm{X}$ PCR buffer, $0.625 \mu \mathrm{L}$ of $50 \mathrm{mM} \mathrm{MgCl}, 0.125 \mu \mathrm{L}$ of $10 \mu \mathrm{M}$ of both primers (each primer set was run in separate reactions), $0.062 \mu \mathrm{L}$ of $10 \mathrm{mM}$ dNTPs, $0.060 \mu \mathrm{L}$ of PlatinumTaq $(5 \mathrm{U} / \mu \mathrm{L})$, and $1 \mu \mathrm{L}$ of undiluted DNA template/reaction (11.5 $\mu \mathrm{L}$ total). A PCR negative control, which consisted of the PCR cocktail with no added DNA, and a positive control which was a previously extracted and successfully amplified dietary supplement or spice, were included with all amplifications. A Mastercycler ep gradient $S$ thermocycler (Eppendorf) was used for all PCRs with the following conditions: $94^{\circ} \mathrm{C}$ for 5 min; 35 cycles of $94^{\circ} \mathrm{C}$ for $1 \mathrm{~min} ; 50^{\circ} \mathrm{C}$ for $1 \mathrm{~min}$; and $72^{\circ} \mathrm{C}$ for $2 \mathrm{~min}$, with a final extension at $72^{\circ} \mathrm{C}$ for $7 \mathrm{~min}$, followed by a $4^{\circ} \mathrm{C}$ hold. All extraction negative controls were also run to confirm that there was no amplification. Amplification success was evaluated using a precast $1.2 \%$ agarose E-gel with ethidium bromide according to the manufacturer's protocol on the E-Base Integrated power supply (Thermo Scientific). Gels were run for $5 \mathrm{~min}$ and then visualized using a $\mathrm{G}$ : box gel documentation system (Syngene).

PCR Cleanup and Sequencing Reaction: Any amplified PCR products were purified by adding $2 \mu \mathrm{L}$ of Exosap-IT (Thermo Scientific) to $5 \mu \mathrm{L}$ of PCR product, and incubating at $37^{\circ} \mathrm{C}$ for $15 \mathrm{~min}$, followed by $15 \mathrm{~min}$ at $80^{\circ} \mathrm{C}$. The same primers used for PCR amplification were used for sequencing (described above). The amplified products were prepared for sequencing using both the forward and reverse primer in separate reactions. Each reaction contained $0.25 \mu \mathrm{L}$ of BigDye Terminator v3.1 (Thermo Scientific), $1.875 \mu \mathrm{L}$ of $5 \mathrm{X}$ sequencing buffer (Life Technologies), $5 \mu \mathrm{L}$ of $10 \%$ trehalose, $1 \mu \mathrm{L}$ of $10 \mu \mathrm{M}$ primer, and $0.875 \mu \mathrm{L}$ of molecular grade water, for a total of $9 \mu \mathrm{L}$, to which $1 \mu \mathrm{L}$ of purified PCR product was added. The sequencing reaction was also performed on a Mastercycler ep gradient $S$ thermocycler with the following conditions: $96^{\circ} \mathrm{C}$ for $2 \mathrm{~min}$; 30 cycles of $96^{\circ} \mathrm{C}$ for $30 \mathrm{~s}, 55^{\circ} \mathrm{C}$ for $15 \mathrm{~s}$; and $60^{\circ} \mathrm{C}$ for $4 \mathrm{~min}$, followed by a $4^{\circ} \mathrm{C}$ hold. Sequencing reaction products were purified using a PERFORMA DTR V3 96-well short plate kit (Edge Bio) and placed in $10 \mu \mathrm{L}$ of Hi-Di formamide (Thermo Scientific). The purification protocol was modified from the manufacturer's instructions, following Handy et al. [44]. At this point, samples were bidirectionally sequenced on an Applied Biosystems Genetic Analyzer $3500 \mathrm{xL}$ capillary sequencer.

Sequence processing: Sequence trace files (.ABI) files were imported into the bioinformatics software Geneious Pro (v7.1.7, Biomatters Ltd.) $[45,46]$. Bidirectional sequences were trimmed and assembled into contigs if possible using the de novo assemble function, the Geneious assembler, and the highest sensitivity/ slow setting. Sequences were trimmed for quality (error probability limit 0.05 and trim from both $3^{\prime}$ and $5^{\prime}$ ends) and manually to remove primer sites. Sequences below $<20 \%$ high quality (HQ) or less than 120 bases were considered failures and not analyzed. Sequences that were either based on a single read and/or between
20-50\% HQ and/or > 2\% ambiguous bases were labeled "low" quality, from $51-80 \% \mathrm{HQ}$ and/or $0.1-2 \%$ ambiguities were labeled "medium" quality, and those which were $>81 \%$ with no ambiguities were labeled "high" quality. All trimmed DNA sequences used for analysis can be found in Table S4, Supporting Information, in FASTA format.

All passing sequences (low-high) were compared to the National Center for Biotechnology Information's (NCBI) Genbank database through Geneious Pro, using the "Sequence Search" function with the following parameters: The non-redundant (nr) database, using the program blastn, with the results listed in a hit table, and the matching regions retrieved. The low complexity filter and mask for lookup table were selected. The word size was 11, the max E-value was $1 \mathrm{e}^{-1}$, the Gap cost (Open Extend) was 52 , and the scoring (Match Mismatch) was set at $2-3$. Ten hits were retrieved in total. The highest percentage match was reported. However, only matches of $98 \%$ or greater were considered accurate.

\section{Supporting information}

Chemical structures, examples of estimation of concentrations of marker compounds from label information, quantitative HPLC and LC-MS method information, and analysis of NIST botanical SRMs and trimmed DNA sequences are available as Supporting Information.

\section{Acknowledgements}

The authors acknowledge the support for the appointment of R. Cheng and N. Shyong through a contract with the Research Participation Program at the CFSAN administered by the Oak Ridge Institute for Science and Education through the contract with the FDA. The authors thank Dr. Jeanne Rader (Retired, FDA) for her valuable assistance in preparation of this manuscript. Authors also express thanks to Dr. Gregory Noonan and Dr. Cara Welch for their comments and review of the manuscript. The assistance of Dr. Satyanarayanaraju Sagi in acquiring the mass spectrometric data is greatly appreciated.

\section{Conflict of Interest}

The authors have declared that they have no conflicting interests.

\section{References}

[1] Bailey RL, Gahche JJ, Miller PE, Thomas PR, Dwyer JT. Why US adults use dietary supplements. JAMA Intern Med 2013; 173: 355-361

[2] Kantor ED, Rehm CD, Du M, White E, Giovannucci EL. Trends in dietary supplement use among US adults from 1999-2012. JAMA 2016; 316: 14641474

[3] Wu CH, Wang CC, Tsai MT, Huang WT, Kennedy J. Trend and pattern of herb and supplement use in the United States: results from the 2002, 2007, and 2012 national health interview surveys. Evid Based Complement Alternat Med 2014; 2014: 872320

[4] Cohen PA. Hazards of hindsight-monitoring the safety of nutritional supplements. N Engl J Med 2014; 370: 1277-1280 
[5] Betz JM, Garland T, Page SW. Safety of botanical dietary supplements. In: Shi j, Mazza G, Le Maguer M, eds. Functional Foods. Boca Raton: CRC Press; 2002

[6] 103rd Congress Public Law 103-417. Dietary Supplement Health and Education Act of 1994. Available at http://www.gpo.gov/fdsys/pkg/STATUTE108/pdf/STATUTE-108-Pg4325.pdf. Accessed July 1, 2015

[7] Food and Drug Administration Federal Register, Vol. 72, No. 121, 34752. Current good manufacturing practice in manufacturing, packaging, labeling, or holding operations for dietary supplements. Available at http:// www.gpo.gov/fdsys/pkg/FR-2007-06-25/pdf/07-3039.pdf. Accessed July 1,2015

[8] Smillie T], Khan IA. A comprehensive approach to identifying and authenticating botanical products. Clin Pharmacol Ther 2010; 87: 175-186

[9] Khan IA, Smillie T. Implementing a "quality by design" approach to assure the safety and integrity of botanical dietary supplements. J Nat Prod 2012; 75: 1665-1673

[10] Chen S, Pang X, Song J, Shi L, Yao H, Han J, Leon C. A renaissance in herbal medicine identification: from morphology to DNA. Biotechnol Adv 2014; 32: 1237-1244

[11] Muhammad Tahir H, Akhtar S. Services of DNA barcoding in different fields. Mitochondrial DNA A DNA Mapp Seq Anal 2016; 27: 4463-4474

[12] Applequist WL, Miller JS. Selection and authentication of botanical materials for the development of analytical methods. Anal Bioanal Chem 2012; 405: 4419-4428

[13] de Boer HJ, Ichim MC, Newmaster SG. DNA barcoding and pharmacovigilance of herbal medicines. Drug Saf 2015; 38: 611-620

[14] Parveen I, Gafner S, Techen N, Murch SJ, Khan IA. DNA barcoding for the identification of botanicals in herbal medicine and dietary supplements: strengths and limitations. Planta Med 2016; 82: 1225-1235

[15] Newmaster SG, Grguric M, Shanmughanandhan D, Ramalingam S, Ragupathy S. DNA barcoding detects contamination and substitution in North American herbal products. BMC Med 2013; 11: 222

[16] New York State Office of the Attorney General. A.G. Schneiderman asks major retailers to halt sales of certain herbal supplements as DNA tests fail to detect plant materials listed on majority of products tested. Available at http://www.ag.ny.gov/press-release/ag-schneiderman-asks-major-retailers-halt-sales-certain-herbal-supplements-dna-tests. Accessed November 2, 2016

[17] Food and Drug Administration. Nutrition labeling of dietary supplements 21CFR101.36. Available at http://www.accessdata.fda.gov/scripts/cdrh/ cfdocs/cfcfr/cfrsearch.cfm?fr=101.36. Accessed 30 Nov 2016

[18] Avula B, Sagi S, Gafner S, Upton R, Wang YH, Wang M, Khan IA. Identification of Ginkgo biloba supplements adulteration using high performance thin layer chromatography and ultra high performance liquid chromatography-diode array detector-quadrupole time of flight-mass spectrometry. Anal Bioanal Chem 2015; 407: 7733-7746

[19] Chandra A, Li Y, Rana J, Persons K, Hyun C, Shen S, Mulder T. Qualitative categorization of supplement grade Ginkgo biloba leaf extracts for authenticity. J Funct Foods 2011; 3: 107-114

[20] United States Pharmacopeia. Powdered ginkgo extract. USP 2015; 38: 6264-6267

[21] Tian Z, Wan M, Wang Z, Wang B. The preparation of genistein and LC-MS/ MS on-line analysis. Drug Dev Res 2004; 61: 6-12

[22] United States Pharmacopeia. Powdered valerian. USP 2015; 38: 62496250

[23] Lucas D, Neal-Kababick J, Zweigenbaum J. Characterization and quantitation of yohimbine and its analogs in botanicals and dietary supplements using LC/QTOF-MS and LC/QQQ-MS for determination of the presence of bark extract and yohimbine adulteration. J AOAC Int 2015; 98: 330-335

[24] Cohen PA, Wang YH, Maller G, DeSouza R, Khan IA. Pharmaceutical quantities of yohimbine found in dietary supplements in the USA. Drug Test Anal 2015; 8: 357-369

[25] Sun J, Chen P. Chromatographic fingerprint analysis of yohimbe bark and related dietary supplements using UHPLC/UV/MS. J Pharm Biomed Anal 2012; 61: 142-149
[26] United States Pharmacopeia. Powdered St. John's wort extract. USP 2015; 38: 6211-6212

[27] Shah AK, Avery BA, Wyandt CM. Content analysis and stability evaluation of selected commercial preparations of St. John's wort. Drug Dev Ind Pharm 2005; 31: 907-916

[28] Ivanova NV, Kuzmina ML, Braukmann TW, Borisenko AV, Zakharov EV. Authentication of herbal supplements using next-generation sequencing. PLoS One 2016; 11: e0156426

[29] Rachmayanti Y, Leinemann L, Gailing O, Finkeldey R. DNA from processed and unprocessed wood: factors influencing the isolation success. Forensic Sci Int Genet 2009; 3: 185-192

[30] Makovetskaya EY. Flavonoids of certain species of Hypericum L. Chem Nat Compd 1999; 35: 582-583

[31] Soares PK, Scarminio IS. Multivariate chromatographic fingerprint preparation and authentication of plant material from the genus Bauhinia. Phytochem Anal 2008; 19: 78-85

[32] Harnly JM, Luthria D, Chen P. Detection of adulterated Ginkgo biloba sup plements using chromatographic and spectral fingerprints. J AOAC Int 2012; 95: 1579-1587

[33] Little DP. Authentication of Ginkgo biloba herbal dietary supplements using DNA barcoding. Genome 2014; 57: 513-516

[34] Sucher NJ, Hennell JR, Carles MC. DNA fingerprinting, DNA barcoding, and next generation sequencing technology in plants. Methods Mol Biol 2012; 862: 13-22

[35] Harbaugh Reynaud D. Next-generation DNA testing for botanicals. Available at http://www.nsf.org/newsroom_pdf/hs_next-generation_dna-testing_botanicals_no.pdf. Accessed December 9, 2016

[36] Palhares RM, Gonçalves Drummond M, Dos Santos Alves Figueiredo Brasil B, Pereira Cosenza G, das Graças Lins Brandão M, Oliveira G. Medicina plants recommended by the World Health Organization: DNA barcode identification associated with chemical analyses guarantees their quality. PLoS One 2015; 10: e0127866

[37] Gray D, LeVanseler K, Meide P, Waysek EH. Evaluation of a method to determine flavonol aglycones in Ginkgo biloba dietary supplement crude materials and finished products by high-performance liquid chromatography: collaborative study. J AOAC Int 2007; 90: 43-53

[38] United States Pharmacopeia. Soy isoflavone tablets. USP 2015; 38: 6231 6233

[39] Lukas D. Application note: sample prep for trace analysis of adulterants in erectile dysfunction dietary supplements. Available at http://www.agilent. com/cs/library/applications/5991-3638EN.pdf. Accessed December 6, 2016

[40] European Pharmacopeia. St. John's wort dry extract, quantified. Ph Eu 2016; 80: 1393-1394

[41] Chen S, Yao H, Han J, Liu C, Song J, Shi L, Zhu Y, Ma X, Gao T, Pang X, Luo K, Li Y, Li X, Jia X, Lin Y, Leon C. Validation of the ITS2 region as a novel DNA barcode for identifying medicinal plant species. PLoS One 2010; 5: e8613

[42] Sang T, Crawford D, Stuessy T. Chloroplast DNA phylogeny, reticulate evolution, and biogeography of Paeonia (Paeoniaceae). Am J Bot 1997; 84: 1120

[43] Tate JA, Simpson BB. Paraphyly of Tarasa (Malvaceae) and diverse origins of the polyploid species. Syst Bot 2003; 28: 723-737

[44] Handy SM, Parks MB, Deeds JR, Liston A, de Jager LS, Luccioli S, KwegyirAfful E, Fardin-Kia AR, Begley TH, Rader JI, Diachenko GW. Use of the chloroplast gene ycf1 for the genetic differentiation of pine nuts obtained from consumers experiencing dysgeusia. J Agric Food Chem 2011; 59: 1099511002

[45] Kearse M, Moir R, Wilson A, Stones-Havas S, Cheung M, Sturrock S, Buxton S, Cooper A, Markowitz S, Duran C, Thierer T, Ashton B, Meintjes P, Drummond A. Geneious Basic: an integrated and extendable desktop software platform for the organization and analysis of sequence data. Bioinformatics 2012; 28: 1647-1649

[46] www.Geneious.com. Available at http://www.geneious.com/. Accessed November 2, 2016 